\title{
Cost optimal investment in energy efficiency measures and energy supply system in a neighbourhood in Norway
}

\author{
Harald Taxt Walnum ${ }^{1 *}$, Marius Bagle ${ }^{1}$, Ase Lekang Sørensen ${ }^{1}$ and Selamawit Mamo Fufa ${ }^{1}$ \\ ${ }^{1}$ SINTEF Community, Architectural Engineering, 0314 Oslo, Norway
}

\begin{abstract}
Building renovation is a key measure to reduce energy consumption and Greenhouse gas (GHG) emissions, and ease the transition to a fully renewable energy system. This paper applies the IEA EBC Annex 75 methodology for investigating the cost optimal and environmental trade-off between investment in energy efficiency measures on the building envelope and energy supply, on a residential neighbourhood in Norway. Combination of different energy efficiency measures and energy supply systems are investigated with an optimal investment model. The cost and environmental impact of the combinations are evaluated. An important outcome is that within the evaluated combinations, the choice of energy supply system has little impact on the cost effectiveness of the energy efficiency measures. However, it has a significant impact on the GHG emissions. The results also highlight the importance of performing energy efficiency measures in coordination with other renovating measures, both regarding cost effectiveness and environmental impact. The results will not give a finite answer to what is the best solution but serves at a useful set of inputs for overall evaluations.
\end{abstract}

\section{Introduction}

Building renovation is a key measure to reduce energy consumption, and GHG emissions, increase resource utilisation, and ease the transition to a fully renewable energy system. Given that the majority of the world's building stock for the next 30 years already exists today, consideration of renovation of existing building stock represents one pathway towards a more sustainable future [1]. Europe's roadmap for making the EU's economy sustainable (The European Green Deal) aims at doubling the renovation rate as important measure to reach the climate neutral goal of 2050 [2]. However, investigating measures at single building level can often result in sub-optimal solutions that are not to the benefit of the overall energy system [3]. The potential impact from renovation of existing buildings can be significant when the results from individual buildings are scaled across district or urban scale. The district scale allows to investigate the cost-effective balance between energy efficiency measures and renewable energy sources at a higher level, by also including district energy solutions. Also working on district or urban scale makes it possible to take advantage of interactions and synergies between different buildings, as well as speeding up the process of reducing energy consumption and associated GHG emissions in the building sector [4].

This work is part of the IEA EBC Annex 75 and applies the developed methodology to find the cost and environmentally optimal balance between energy efficiency measures on the building envelope and renewable energy for heating.

\section{Method}

IEA EBC Annex 75 focus on cost-effective building renovation at district level combining energy efficiency measures and renewables. Within the Annex, a methodology is developed for assessing the most costeffective balance between energy efficiency measures and measures on the energy supply system. TerésZubiaga et al [5] present the key elements of the methodology and show how it can be successfully applied at a Portuguese district. An extensive description is to be published at the Annex 75 website [6]. Below, a brief description of the assessment procedure is given.

\subsection{The Annex 75 assessment procedure}

The first step of the assessment is the definition and characterization of investigated districts. This involves gathering information of the existing (and potentially planned new) buildings and district solutions, such as building dimensions and envelope parameters, existing energy supply system etc.

The second step is to define and assess the reference case. The reference case should be based on the current status of the district but include the cost of "anyway"renovations. Anyway-renovations are renovations that are necessary for restoring or sustaining the functionality of the buildings, but without related energy efficiency measures. This could be painting of facades or repairing roofs. It also includes necessary renovations or replacement of the existing energy supply system.

The third step is the definition and assessment of renovation scenarios. This involves defining sets of renovation measures for improved energy efficiency of

\footnotetext{
* Corresponding author: harald.walnum@sintef.no
} 
the buildings and alternative solutions for the energy supply systems. Different scenarios for energy efficiency measures and energy supply systems are combined in the solutions and assessed with regards to cost, energy consumption and GHG emissions. The evaluated energy efficiency measures and energy supply systems are described in section 3.2 and 3.3, respectively.

The key parameters that are considered in the assessment are: annualized cost (EUR/year), annual GHG emissions $\left(\mathrm{kgCO}_{2} /\right.$ year $)$ and annual primary energy consumption ( $\mathrm{kWh} /$ year).

\subsection{Building simulation}

The building energy demands for the reference case and all the energy efficiency measure scenarios are calculated with the simulation tool SIMIEN [7]. SIMIEN is a Norwegian building energy simulation tool often used for validation against national building regulations. The tool provides hourly energy profiles for heating, cooling, and electricity demand. These profiles are then used for energy supply system analysis. For this case, 31 individual buildings are modelled.

\subsection{Energy supply system evaluation}

The assessment of different solutions for energy supply systems are performed with the cost optimization tool BUTLER. BUTLER is a two-stage deterministic Mixed-Integer Linear Program is used to find the optimal technology sizes while taking a series of costs into consideration. In addition, the cost of operation is minimized, given time series of costs, efficiencies and load profiles for energy use [8]. Below, the main equations of the optimization problem are shown. The parameters and variables are defined in Table 1.

First, consider the optimization problem as consisting of two stages, with the objective function:

$$
\min \left(c^{\mathrm{inv}}+c^{\mathrm{op}}\right)
$$

Where $c^{\text {inv }}$ is the cost of investing in the technologies, and $c^{\text {op }}$ is the cost of operation. The terms are written out as

$$
\begin{aligned}
c^{\mathrm{inv}}= & \sum_{i \in \mathcal{J}} x_{i} C_{i}^{\mathrm{inv}}+\delta_{i} C_{i}^{\mathrm{fxd}} \\
c^{\mathrm{op}}=\sum_{i \in \mathcal{J}} x_{i} C_{i}^{\mathrm{run}} & +\sum_{t \in \mathcal{T}} d h_{i, t} P^{\mathrm{dh}}+\sum_{t \in \mathcal{T}} y_{t}^{\mathrm{imp}} P^{\mathrm{el}} \\
& -\sum_{t \in \mathcal{T}} y_{t}^{\mathrm{exp}} P^{\mathrm{spot}}
\end{aligned}
$$

Where $\mathcal{J}$ is the set of available technologies and

$$
P^{\mathrm{el}}=P^{\mathrm{spot}}+P^{\mathrm{grid}}+P^{\mathrm{tax}}
$$

Furthermore, we have the balancing constraints $\forall t \in \mathcal{T}$ :

$$
\begin{aligned}
D_{t}^{\mathrm{el}}=y_{t}^{\mathrm{imp}}-y_{t}^{\mathrm{exp}} & -\sum_{i \in \mathcal{J}_{e \ell}}\left(y_{i, t}^{\mathrm{sh}}+y_{i, t}^{\mathrm{dhw}}\right)+y_{t}^{\mathrm{pv}} \\
D_{t}^{\mathrm{sh}} & =\sum_{i \in \mathcal{J}} q_{i, t}^{\mathrm{sh}}+q_{t}^{\mathrm{hs}} \\
D_{t}^{\mathrm{dhw}} & =\sum_{i \in \mathcal{J}} q_{i, t}^{\mathrm{dhw}}+q_{t}^{\mathrm{hwt}}
\end{aligned}
$$

Furthermore, the production in each time step must be limited to the installed capacity $\forall t \in \mathcal{T}, \forall i \in \mathcal{J}$ :

$$
q_{i, t}^{\mathrm{sh}}+q_{i, t}^{\mathrm{dhw}}=q_{i, t}^{\mathrm{ht}} \leq x_{i}
$$

In addition, efficiencies must be respected $\forall t \in \mathcal{T}, \forall i \in$ $\mathcal{J}_{e l} \backslash \mathcal{J}_{h p}$, where $\mathcal{J}_{h p}=\{A S H P, G S H P, A 2 A\}$ :

$$
\begin{aligned}
q_{i, t}^{\mathrm{sh}} & =\eta_{i} y_{i, t}^{\mathrm{sh}} \\
q_{i, t}^{\mathrm{dhw}} & =\eta_{i} y_{i, t}^{\mathrm{dhw}}
\end{aligned}
$$

For $\forall t \in \mathcal{T}, \forall i \in \mathcal{J}_{h p}$ :

$$
\begin{gathered}
q_{i, t}^{\mathrm{sh}}=\operatorname{CO}_{i, t}^{\mathrm{sh}} y_{i, t}^{\mathrm{sh}} \\
q_{i, t}^{\mathrm{dhw}}=\operatorname{CO}_{i, t}^{\mathrm{dhw}} y_{i, t}^{\mathrm{dhw}}
\end{gathered}
$$

For the heat pump $A 2 A, \operatorname{CO}_{A 2 A, t}^{\mathrm{dhw}}=0 \forall t \in \mathcal{T}$, i.e. it only delivers space heating. For the case with a centralized distribution system ("cen_dh" and "cen_gshp"), the following holds $\forall t \in \mathcal{T}$ :

$$
\operatorname{COP} P_{g s h p, t}^{\mathrm{sh}}=\operatorname{CO} P_{g s h p, t}^{\mathrm{dhw}}
$$

i.e. the heat is delivered at the same temperature, irrespective of use. Hence, equations (space heating and dhw) can be merged, which yields a total heat balance:

$$
D_{t}^{\mathrm{ht}}=\sum_{i \in \mathcal{J}} q_{i, t}^{\mathrm{ht}}+q_{t}^{\mathrm{hs}}
$$

where $q_{t}^{\text {hs }}$ can be viewed as the heat released from a central heat storage tank.

To force satisfactory backup in heat pump systems as discussed in section 3.3, the following constraints are introduced for the point source and waterborne systems, respectively.

$$
x_{E R H} \geq \max \left(D_{t}^{\mathrm{sh}}\right)
$$

$$
x_{E B} \geq \max \left(D^{\mathrm{sh}}+D^{\mathrm{dhw}}\right)
$$

For the PV, we have

$$
y_{p v, t}=x_{p v} Y_{p v, t}
$$

$\underline{\text { Heat storage }}$ 
A heat storage $i \in\{H S, H W T\}$ is defined by the following equations $\forall t \in \mathcal{T}$ :

$$
\begin{gathered}
z_{i, t} \leq x_{i} \\
z_{i, t}=z_{i, t-1}\left(1-\beta_{i}^{\text {loss }}\right)+q_{t}^{i} \\
-\beta_{i}^{\text {ch }} x_{i} \leq q_{t}^{i} \leq \beta_{i}^{\text {ch }} x_{i}
\end{gathered}
$$

In addition, the end-state must be equal to the initial state:

$$
z_{i, 0}=z_{i,|\mathcal{T}|}
$$

Heat pump model

The coefficient-of-performance (COP) and availability factor $(\mathrm{P})$ for each heat pump type is found by linearizing between operating points given in the Norwegian standard SN-NSPEK 3031 [9]. The COPs used as base for these interpolations are 3.00, 4.55 and 4.59 for the A2A, ASHP and GSHP, respectively.

\section{$\underline{\text { PV systems }}$}

The performance of the PV system is pre calculated and imported as a timeseries with hourly production per $\mathrm{kW}_{\text {peak }}$ installed. Details of the PV performance calculations can be found in [10].

\section{$\underline{\text { Distribution system }}$}

Distribution of hot water for thermal energy use is modelled as a fixed heat loss. Heat loss from the distribution system will be vary with both distribution temperature and ambient temperature, but a constant

\begin{tabular}{|c|c|c|}
\hline Pars & Description & Unit \\
\hline$C_{i}^{\mathrm{inv}}$ & Specific investment cost, $i \in \mathcal{J}$ & $€ / \mathrm{kW}$ \\
\hline$C_{i}^{\text {fxd }}$ & Fixed investment cost, $i \in \mathcal{J}$ & $€$ \\
\hline$C_{i}^{\text {run }}$ & $\begin{array}{c}\text { Operating cost, } i \in \mathcal{J} \text { (\% of } \\
\left.C_{i}^{\text {inv }}\right)\end{array}$ & - \\
\hline$P^{\mathrm{dh}}$ & Energy cost, district heating & $€ / \mathrm{kWh}$ \\
\hline$P^{\mathrm{el}}$ & Energy cost, electricity & $€ / \mathrm{kWh}$ \\
\hline$P^{\text {spot }}$ & Electricity spot price & $€ / \mathrm{kWh}$ \\
\hline$P^{\text {grid }}$ & (EP) grid tariff (+ konstant ledd) & $€ / \mathrm{kWh}$ \\
\hline$P^{\operatorname{tax}}$ & Electricity tax (el-avgift) & $€ / \mathrm{kWh}$ \\
\hline$\beta_{i}^{\text {loss }}$ & Heat storage loss from & - \\
\hline$\beta_{i}^{\text {ch }}$ & Heat storage charge rate limit & - \\
\hline$C O P_{i, t}^{\text {sh }}$ & $\mathrm{COP}$ for SH at time step $t, \forall i \in J_{h p}$ & - \\
\hline$C O P_{i, t}^{\mathrm{dhw}}$ & COP for DHW at time step $t, \forall i \in J_{h p}$ & - \\
\hline$\eta_{i}$ & Efficiency, $\forall i \in \mathcal{J} \backslash \mathcal{J}_{h p}$ & - \\
\hline$D_{t}^{\text {el }}$ & Specific electric load at $t \in \mathcal{T}$ & $\mathrm{kW}$ \\
\hline$D_{t}^{\text {sh }}$ & Space heating load at $t \in \mathcal{T}$ & $\mathrm{kW}$ \\
\hline$D_{t}^{\text {dhw }}$ & Domestic hot water load at $t \in \mathcal{T}$ & $\mathrm{kW}$ \\
\hline$Y_{p v, t}$ & Potential PV-production at $t \in \mathcal{T}$ & $\mathrm{kWp} / \mathrm{kW}$ \\
\hline \multicolumn{3}{|l|}{ Vars } \\
\hline$x_{i}$ & Installed capacity, $i \in \mathcal{J}$ & $\mathrm{kW}(\mathrm{h})$ \\
\hline$\delta_{i}$ & Binary activation variable for $i \in \mathcal{J}$ & - \\
\hline$d h_{i, t}$ & District heat import at $t \in \mathcal{T}$ & $\mathrm{kW}$ \\
\hline$y_{t}^{\text {imp }}$ & Electricty import at $t \in \mathcal{T}$ & $\mathrm{kW}$ \\
\hline$y_{t}^{\exp }$ & Electricty export at $t \in \mathcal{T}$ & $\mathrm{kW}$ \\
\hline$y_{i, t}^{\text {sh }}$ & Electricity for $\mathrm{SH}, i \in \mathcal{J}_{e l}, t \in \mathcal{T}$ & $\mathrm{kW}$ \\
\hline$y_{i, t}^{\text {dhw }}$ & Electricity for DHW, $i \in \mathcal{J}_{e l}, t \in \mathcal{T}$ & $\mathrm{kW}$ \\
\hline$y_{t}^{\mathrm{pv}}$ & Electricity from $\mathrm{PV}, t \in \mathcal{T}$ & $\mathrm{kW}$ \\
\hline
\end{tabular}
heat loss is found to be at better assumption than a fraction of delivered heat.

Table 1: Parameters and variables in the BUTLER model

\begin{tabular}{|c|c|c|}
\hline$q_{i, t}^{\text {sh }}$ & Heat for SH from $i \in \mathcal{J}, t \in \mathcal{T}$ & $\mathrm{kW}$ \\
\hline$q_{i, t}^{\text {dhw }}$ & Heat for DHW from $i \in \mathcal{J}, t \in \mathcal{T}$ & $\mathrm{kW}$ \\
\hline$q_{t}^{\text {hs }}$ & Heat from HS, $t \in \mathcal{J}$ & $\mathrm{kW}$ \\
\hline$q_{t}^{\text {ht }}$ & Heat from HWT, $t \in \mathcal{T}$ & $\mathrm{kW}$ \\
\hline$z_{i, t}$ & SOC for $i \in\{H S, H W T\}, t \in \mathcal{T}$ & $\mathrm{kWh}$ \\
\hline
\end{tabular}

\section{The case study}

\subsection{Description of the neighbourhood}

The selected case study is a housing cooperative located in the central part of Norway. The neighbourhood was developed in 1970s and consists of about 1000 apartments. The façades and roofs were renovated in the mid-1990s. As part of this renovation, an extra layer of insulation of 10 and $5 \mathrm{~cm}$ was added to the façades and roofs, respectively. No façade refurbishment is therefore included in the reference scenario. The windows are of similar age and is expected to be replaced within near future. A new set of windows with the same thermal properties as the existing once is therefore included in the reference scenario.

The heat is supplied through a district heating system. The district heating is distributed from a primary substation (P-sub) to 20 secondary substations (S-sub) through three main distribution lines. At the Ssubs, the heat is split into separate circuits for space heating $(\mathrm{SH})$ and domestic hot water (DHW). More details on the layout can be found in [11].

The heat supply system, from the P-sub to the radiators are in need of renovation, and estimated costs of this are included in the relevant scenarios.

For this case study it was decided to study one of the three branches from the P-sub. This branch supplies $30490 \mathrm{~m}^{2}$ gross heated floor area (GHFA) which is about $30 \%$ of the total GHFA of the neighbourhood. It consists of 6 S-subs, 34 buildings and a total of 351 apartments.

\subsection{Evaluated measures on the building envelope}

A total of five different energy efficiency measures on the building envelope are evaluated (

Table 2).

Table 2: Evaluated energy efficiency measures.

\begin{tabular}{|c|c|}
\hline Name & Description \\
\hline F1 & $\begin{array}{c}\text { Add } 10 \mathrm{~cm} \text { insulation of façades. Reduces U- } \\
\text { value from } 0.27 \text { to } 0.18 \mathrm{~W} / \mathrm{m}^{2} \mathrm{~K}\end{array}$ \\
\hline $\mathrm{R} 1$ & $\begin{array}{c}\text { Add } 5 \mathrm{~cm} \text { insulation of roof. Reduces U-value } \\
\text { from } 0.18 \text { to } 0.05 \mathrm{~W} / \mathrm{m}^{2} \mathrm{~K}\end{array}$ \\
\hline $\mathrm{W} 0$ & $\begin{array}{c}\text { Replace existing windows with new window } \\
\text { this same thermal properties }\left(1.6 \mathrm{~W} / \mathrm{m}^{2} \mathrm{~K}\right)\end{array}$ \\
\hline $\mathrm{W} 1$ & $\begin{array}{c}\text { Install new windows with U-value of } \\
1.2 \mathrm{~W} / \mathrm{m}^{2} \mathrm{~K} \text { instead of the existing } 1.6 \mathrm{~W} / \mathrm{m}^{2} \mathrm{~K}\end{array}$ \\
\hline $\mathrm{W} 2$ & $\begin{array}{c}\text { Install new windows with U-value of } \\
0.8 \mathrm{~W} / \mathrm{m}^{2} \mathrm{~K} \text { instead of the existing } 1.6 \mathrm{~W} / \mathrm{m}^{2} \mathrm{~K}\end{array}$ \\
\hline $\mathrm{V} 1$ & $\begin{array}{c}\text { Install heat recovery ventilation with thermal } \\
\text { efficiency of } 85 \%\end{array}$ \\
\hline
\end{tabular}


The energy efficiency measures (given under

Table 2) are composed of five different renovation scenarios, in addition to the reference scenario. These are denoted $\mathrm{c} 01-\mathrm{c} 05$ according to Table 3.

Table 3: Scenarios for energy efficiency measures

\begin{tabular}{|c|c|}
\hline Scenario & Energy efficiency measures \\
\hline Ref & $\mathrm{W} 0$ \\
\hline $\mathrm{c} 01$ & $\mathrm{~W} 1$ \\
\hline $\mathrm{c} 02$ & $\mathrm{~W} 2$ \\
\hline $\mathrm{c} 03$ & $\mathrm{~F} 1+\mathrm{R} 1+\mathrm{W} 1$ \\
\hline $\mathrm{c} 04$ & $\mathrm{~F} 1+\mathrm{R} 1+\mathrm{W} 2$ \\
\hline $\mathrm{c} 05$ & $\mathrm{~F} 1+\mathrm{R} 1+\mathrm{W} 2+\mathrm{V} 1$ \\
\hline
\end{tabular}

\subsection{Evaluated energy supply systems}

Five different heat supply systems are considered. They are split into three main heat distribution concepts: central distribution (cen), decentral waterborne distribution (wb) and point source (ps).

The central distribution concept (cen) is based on utilization of the district heating network already in place, with a central heat production/distribution from the existing P-sub. Two heat production systems are considered for this option: renovation of the existing DH substation or installation of a ground source heat pump system (GSHP).

The decentral waterborne distribution (wb) concept is based on installation of new heat production units at the location of the existing S-subs, discarding the P-sub and the distribution system between the P-sub and the Ssubs. GSHP and air source heat pump (ASHP) systems are considered for this option. For both "cen" and "wb" options, the system can invest in hot water tanks (HWT) for energy storage. There are no HWTs present in the current system. The "cen" and "wb" scenarios also need to invest in a renovation of the existing hydronic heating (HY) systems inside the buildings. All heat pump systems are designed with the heat pump as a base load unit and an electric boiler (EB) as backup and peak load. To ensure full backup from the EB, the capacity is forced to be equal to the peak demand, according to equations 15 and 16 .

The point source (ps) concept is based on individual heat supply to each individual apartment. This requires installation of individual hot water boilers for DHW production (EB DHW) and a combination of electric resistance heaters (ERH) and air-to-air heat pumps (A2A) for space heating. Similar as for the waterborne heat pump systems, ERH are dimensioned to cover the full space heating demand.

All the different heat supply systems are coupled with all the energy efficiency measure scenarios, yielding a total of 25 cases.

In addition, all cases are modelled with and without a solar PV system. An evaluation of the performance of a PV system for this neighbourhood was performed by Sorensen et al. [10]. The hourly production profile from this study is used as input to the system optimization tool. As investment in solar PV is not cost effective under the predefined conditions, the model is forced to invest in a fixed size PV system. Based on the result from Sorensen et al. [10], a total system size of $600 \mathrm{~kW}_{\mathrm{p}}$ $\left(4080 \mathrm{~m}^{2}\right)$ is used.

\subsection{GHG emission calculation}

Life cycle assessment methodology is used to evaluate GHG emissions. A functional unit of $1 \mathrm{~m}^{2}$ of heated floor area over 60 years' service life. The system boundary is defined following the life cycle modular principles as outlined in EN15978 [12]. The modular life cycle principle includes four main life cycle stages: product stage (Modules A1-A3), construction stage (Modules A4-A5), use stage (Modules B1-B7) and end of life stage (Modules C1-C4). In addition, the optional stage (Module D) account for the consequences on reuse, recycling and energy recovery outside of the system boundary. In this study, the system boundary is limited to modules A1-A3 (where A1 - raw material supply, A2 - transport and A3 - manufacturing) and B6 (operational energy use). The life cycle impact is calculated in terms of Global warming potential (GWP) measured in $\mathrm{CO}_{2 \text { eq. }}$.

\subsection{Input data}

This section lists the most important input data for the assessment of energy efficiency measure scenarios. Table 4 gives an overview of input data on cost and embodied emissions (GWP) .

Table 4: Input data for assessment of energy efficiency measure scenario

\begin{tabular}{|c|c|c|}
\hline Case & $\begin{array}{c}\text { Cost } \\
{[\mathbf{k E U R}]}\end{array}$ & $\begin{array}{c}\mathbf{G W P} \\
{\left[\mathbf{k g C O} \mathbf{O}_{\mathbf{2} \mathbf{q}} / \mathbf{y}\right]}\end{array}$ \\
\hline $\mathrm{ref}$ & 5597 & 14490 \\
\hline $\mathrm{c} 01$ & 5702 & 14490 \\
\hline $\mathrm{c} 02$ & 5911 & 14490 \\
\hline $\mathrm{c} 03$ & 10890 & 23832 \\
\hline $\mathrm{c} 04$ & 11099 & 23832 \\
\hline $\mathrm{c} 05$ & 13538 & 26170 \\
\hline
\end{tabular}

Cost data for renovations and technologies are collected from data published by the Norwegian Energy Agency [13] and a national construction cost database (Norwegian Pricebook) [14]. Norwegian Pricebook is a cost database which contains cost of a building project, as well as GHG emission and life cycle costs per year building. In addition, case specific costs where collected separately by Sartori et.al [15]. The embodied GHG emission factors for A1-A3 life cycle stages of façade and roof elements are taken from average Norwegian Environmental product declaration (EPD) data [16]. For energy systems, embodied GHG emission factors from the Norwegian Pricebook are used.

Table 5 shows the fixed and specific investment costs and estimated lifetime of each technology used in the economic optimization.. The cases with a centralized distribution systems ("cen") have an additional maintenance cost of $72000 € /$ year, which covers renovation of the central heat distribution system. 
Table 5: Investment cost parameters for assessment of energy supply system solutions

\begin{tabular}{|c|c|c|c|}
\hline & $\begin{array}{c}\text { Fix. } \\
{[€ / \text { per }} \\
\text { unit }]\end{array}$ & $\begin{array}{c}\text { Spec. } \\
{[€ / \mathrm{kW}]}\end{array}$ & $\begin{array}{c}\text { Lifetime } \\
{[\text { years }]}\end{array}$ \\
\hline Common & \multicolumn{3}{|}{} \\
\hline PV & - & 1182 & 25 \\
\hline HWT & - & 125 & 20 \\
\hline PS & \multicolumn{3}{|l}{} \\
\hline ERH & 3000 & - & 20 \\
\hline EB DHW & 3500 & - & 20 \\
\hline A2A & 570 & 671.9 & 20 \\
\hline WB & \multicolumn{3}{|l}{} \\
\hline ASHP & - & 744 & 20 \\
\hline GSHP & - & 1628 & 20 \\
\hline EB & - & 154 & 20 \\
\hline HY & 585000 & - & 30 \\
\hline CEN & \multicolumn{3}{|l}{} \\
\hline DH & 240000 & - & 50 \\
\hline GSHP & - & 1628 & 20 \\
\hline HY & 3510000 & - & 30 \\
\hline
\end{tabular}

The energy costs are based partly on the Annex 75 template (assumption of constant spot price), and partly on reported prices for the regional system operator Tensio (grid tariffs) [17]. A discount for district heating is assumed, with basis in local conditions and Norwegian law [18]. The currency conversion rate used is $0.1 € / \mathrm{NOK}$. The energy prices are shown in Table 6 .

Table 6: Energy prices

\begin{tabular}{|c|c|c|}
\hline Name & $\begin{array}{c}\text { Fixed }[€ / \text { per } \\
\text { unit] }\end{array}$ & Spec. $[€ / \mathrm{kWh}]$ \\
\hline$P^{\mathrm{el}}$ & - & - \\
\hline$P^{\text {spot }}$ & - & 0.04 \\
\hline$P^{\text {grid }}$ & 255 & 0.042 \\
\hline$P^{\text {tax }}$ & - & 0.0163 \\
\hline$P^{\text {dh }}$ & & $P^{\mathrm{el}}-0.01$ \\
\hline
\end{tabular}

According to the Norwegian standard for GHG calculations for buildings [19], the GHG emission assessment from operational energy use should be performed with two emission factors for electricity, one with Norwegian energy consumption mix (NO) and one with an European energy consumption mix (EU28). Both should be estimated averages within the assessment period. This yields the following factors: $\mathrm{NO}=17 \mathrm{gCO} 2 / \mathrm{kWh}$ and $\mathrm{EU} 28=123 \mathrm{gCO} 2 / \mathrm{kWh}$. The corresponding emission factors for district heating are based on estimated production mix in 2030 from the local DH company: $\mathrm{NO}=11 \mathrm{gCO} 2 / \mathrm{kWh}$ and EU28 $=35$ $\mathrm{gCO} 2 / \mathrm{kWh}[20]$. The emission factor for $\mathrm{DH}$ is very low, since about $75 \%$ of the heat is generated from waste incineration, and the emission from this process is not allocated to the DH. This is further discussed below.

\section{Results and discussion}

\subsection{Energy demand}

This section summerizes the results from evaluation of energy demand of the buildings. Figure 1 shows the yearly heat and electricity demand (red) and peak heat and electricity demand (blue) of the buildings. The reference case has a total heat demand of about 3600 MWh/year. This corresponds to about 118 $\mathrm{kWh} / \mathrm{m}^{2} /$ year. Adding about $300 \mathrm{MWh} /$ year in heat loss between the S-subs and the apartments, this is in the lower range of what was measured (average 127 $\mathrm{kWh} / \mathrm{m}^{2} /$ year) by Sørensen et al. [11]. This is expected as the simulations does not take user behaviour into account. The effect of the energy efficiency measures is shown by the reduced energy demand for heating for the different scenarios. Installing the most energy efficient windows (c02) yields a reduction of about $10 \%$. A similar effect can be seen with increased insulation (c03). The combination (c04) yields a reduction of $16 \%$. Adding heat recovery ventilation increases the reduction to $43 \%$. The electricity demand is similar for all the cases except for $\mathrm{c} 05$, due to the fans of the ventilation system.
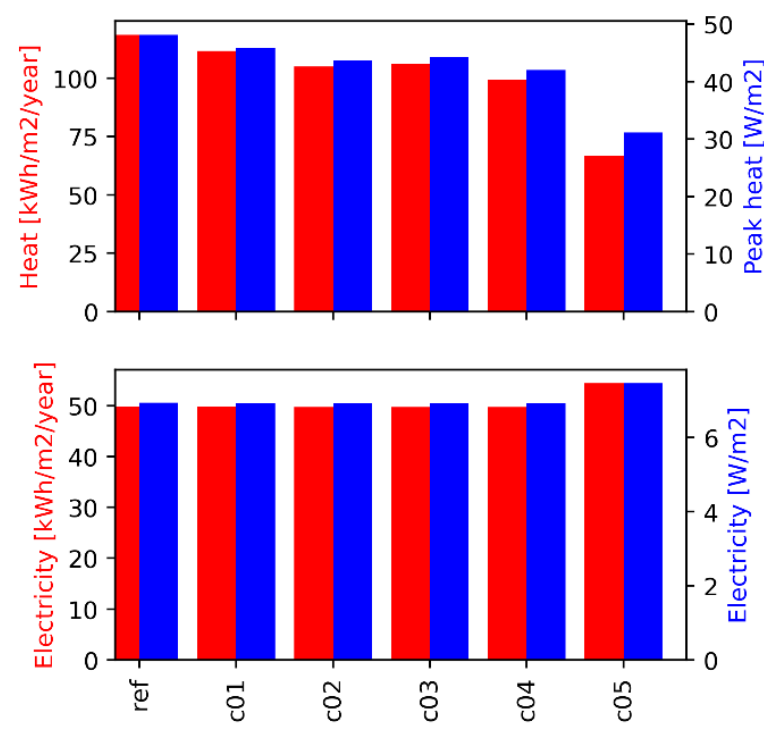

Figure 1: Yearly (red) and peak (blue) heat and electricity demand for the energy efficiency measure scenarios.

\subsection{Energy supply system evaluation}

This section summarizes the results from the energy system evaluation.

Figure 2 and Figure 3 shows the annual costs vs. the GHG emissions from operational energy use with NO and EU28 emission factors, respectively. The filled markers show results for cases without PV installation, while the markers without filling show results with PV. The marker shape indicates the renovation case, while the marker colour indicates the energy system.

From the results, one can see that the choice of energy supply system has little impact on the cost effectiveness of the energy efficiency measures. For all energy supply systems, solutions c01and c02 together with the reference case, have the lowest annual cost, with very small differences. In most cases the option with the best windows (c02) is most cost effective. In general, the results indicate that for this case it is not cost efficient to perform energy efficiency measures when 
they are not performed in relation to other necessary measures (anyway renovations). For the different energy supply systems solutions, the point source option (ps) is most cost efficient, but the difference is small compared to the GSHP and AHSP. As expected, one can see that investment in a PV system is not cost efficient, however the additional annual cost is small.

Looking at the GHG emissions from operational energy, the choice of emission factors for the energy system is very important factor in the analysis of the results for the $\mathrm{DH}$ solution. With the $\mathrm{NO}$ emission factor, the DH cases have the highest emissions, while with the EU28 emission factor, they have the lowest. In general, the lowest operational emissions are achieved with the cases with lowest energy consumption. However, it is interesting to see that it is more cost efficient to invest in a PV system than performing comprehensive energy efficiency measures, such as adding insulation to the façade and roof, or installing heat recovery ventilation.

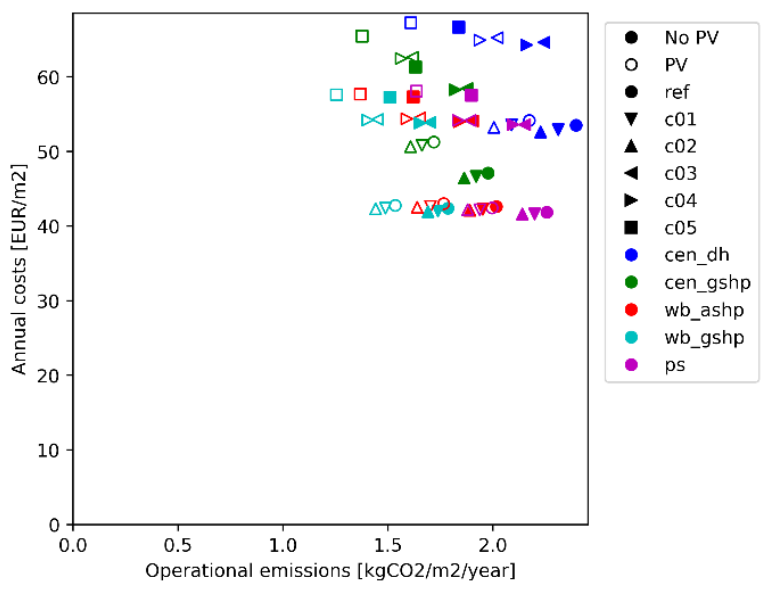

Figure 2: Annual costs vs operational emissions with NO emission factors

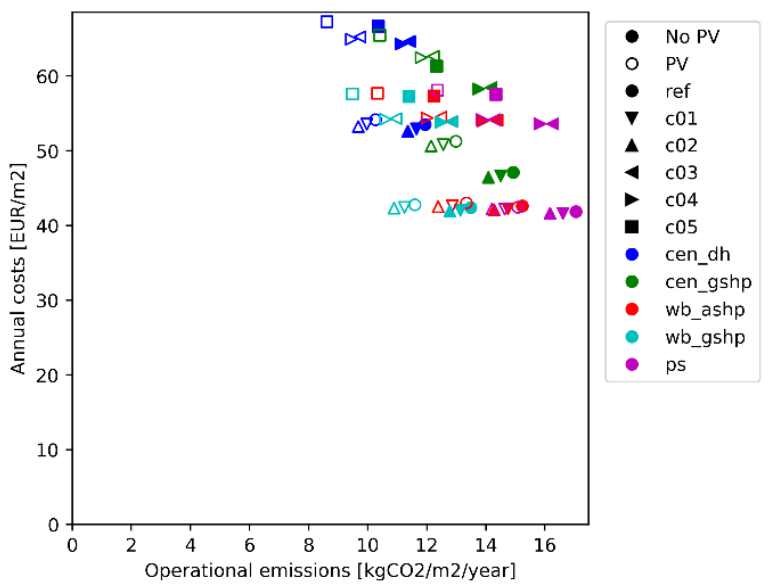

Figure 3: Annual costs vs operational emissions with EU28 emission factors

The amount of self-consumption of the energy produced by the install PV system is important as the selling price for exported electricity is equal to the spot price only and does not include the grid tariff. The import/export balance is calculated on neighbourhood level, and not on individual apartment. This is currently not allowed according to the national regulations, but it is expected that this will change in the future. For the "dh" cases, the self-consumption is about $83 \%$ while it ranges from 91 to $97 \%$ for the others.

For the solutions with heat pumps, the model is forced to have a peak/backup source that can cover the full demand but can invest in the optimal size of the heat pump, with respect to minimum cost. Figure 4 shows the percentage share of the heat demands that are covered by the heat pumps for case "c02". For all the waterborne systems ("cen" and "wb") the coverage is about $85 \%$, while it is significantly lower for the A2A heat pump as it cannot cover DHW demand. The ASHP has slightly lover coverage than the GSHPs, as its capacity is reduced with reduced outdoor temperature.

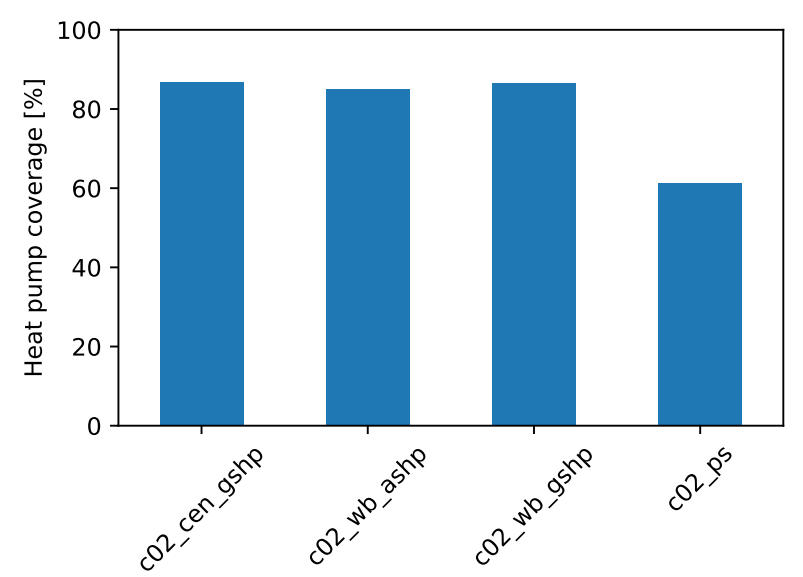

Figure 4: Heat pump coverage of overall heat demand for "c02"

Figure 5 and Figure 6 show the same results as Figure 2 and Figure 3, but include the embodied emissions.

When including the embodied emissions, one can see that the positive effect of reducing the energy demand by adding insulation (c03 and c04) is reduced, due to the emissions from the materials. With the low emission factor for electricity (NO), the total emissions are actually higher, with improved insulation. For the cases with new windows only (c01 and $\mathrm{c} 02$ ), there is no effect, as the same GWP value is used for all window types. One would expect that more materials are needed for more efficient windows, which would result in higher GWP values.

In general, including the embodied emissions emphasises the results from the economic perspective, in that energy efficiency measures should be coordinated with other necessary renovation or rehabilitation works. That is, from both an economical and environmental perspective it makes most sense to improve the energy efficiency of a building component when it needs renovation anyway. 


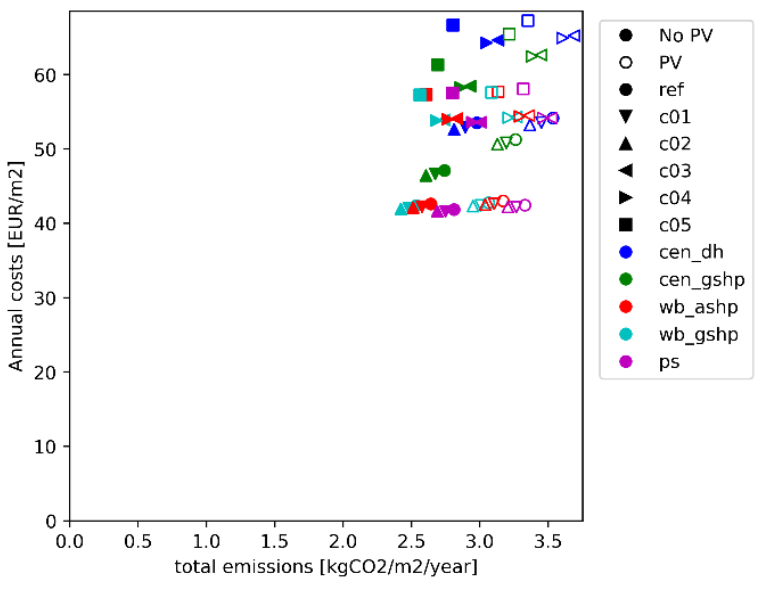

Figure 5: Annual costs vs total emissions with NO factors

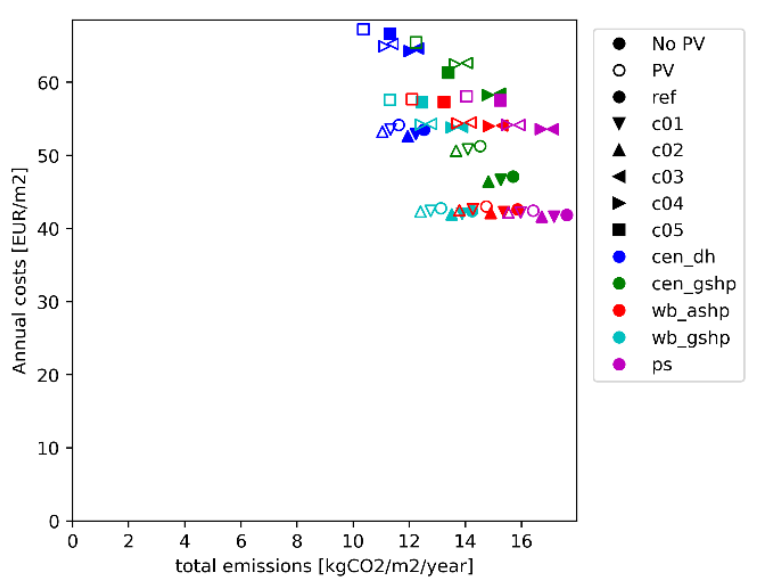

Figure 6: Annual costs vs total emissions with EU28 factors

\subsection{Evaluation of solutions}

From the results, it is difficult to draw a single conclusion of what solution is best. It depend on the overall goal of the decision makers. Furthermore, social factors such as user acceptance and visual expression are important as part of the evaluation. An important benefit with keeping the DH solution is the low maintenance demands. For a private housing cooperative, low operation and maintenance demands could be a significant factor, beyond the direct economic impact that is already included in the analysis. Looking at a large-scale perspective with EU28 emission factors, a solution with new energy efficient windows, a PV installation and renovation of existing DH network might be an overall good solution. However, this conclusion is very much dependent on the assumption of zero GHG emission allocation to production of district heating from waste incineration. This assumption is under continuous debate, Allocation of GHG emissions from waste incineration to the $\mathrm{DH}$ production would give this solution the highest emissions. The same effect can be seen from the embodied emissions for the PV installations. With the applied emission factor, the GHG emissions per produced energy is about $52 \mathrm{gCO}_{2 \mathrm{eq}} / \mathrm{kWh}$. This is higher than the emission factor for electricity, with the national Norwegian energy mix, but lower than the EU28 factor. According to the national Norwegian standard [19] the emission factor ranges from 13 to 190 . This shows the importance of choosing products with minimum embodied emissions related to materials and production. In addition, the source of background emission data and methodological choices have significant impact on GHG emission results.

\subsection{Limitations and implicatoins}

The authors acknowledged that the findings from this study are limited and have a number of uncertainties in both the input assumptions and calculation methods. Thus, the study has highlighted the limitations and areas that need further work as follows.

Most of the cost data is based on general empirical values or superficial evaluations. As a next step it will be natural to do a sensitivity analysis on the most important cost factors.

For GHG emission calculation, the system boundary is limited to A1-A3 and B6 life cycle stages and the background data is mainly based on generic emission factors. Further study is needed to evaluate the environmental impact from the whole life cycle with more specific background data and scenario analysis.

For the GSHP systems, large areas for boreholes are necessary. Available areas are available within the neighbourhood, however detailed analysis of the ground has not been performed. Ground properties, such as vertical distance to bedrock or ground water can have significant influence on the cost.

For the systems with fully or partially centralized heat production systems based on electricity ("cen_gshp" and "wb"), there might be additional costs related to upgrading the electric power supply. Depending on the circumstances this could be significant costs.

There are some physical constraints that are not considered directly in the analysis.

It is assumed that there is available space in the existing buildings, where the primary and secondary substations are located, to install heat pumps. If more space is needed, this could completely change the calculated investment costs. With ASHPs and A2A HPs it is also a question about noise and vibrations. It might not be feasible to find adequate locations for the outdoor units. This is especially true for the A2A HPs as it from a visual point of view is not desirable to have a lot of outdoor units scattered all over the façades.

The BUTLER model is an economic optimization model and could in principle just output the most costeffective solution. To evaluate the trade-off between cost-effectiveness and environmental impact, it is forced to produce out for several fixed systems. However, since the model finds the most cost-effective solution for each system, it might be interesting solutions within each system with lower emissions but at a higher cost. This could e.g., be installation of a larger heat pump, to reduce electricity consumption. 


\section{Conclusions}

This study evaluated different energy efficiency measures on the building envelope in combination with anyway renovations and solutions for the energy supply system for a cooperative housing neighbourhood in Norway.

The results from evaluated cases reveals that the choice of energy supply system has little impact on the cost effectiveness of the energy efficiency measures.

The results also highlight the importance of performing energy efficiency measures in coordination with other renovating measures, both in regard to cost effectiveness and environmental impact. The study

Even if it is difficult to give decisive answer to what is the best solution, this study serves as a useful set of inputs for overall evaluations of investment plans.

The work presented in this paper has been developed by the authors as a contribution to the IEA EBC Annex 75 project. The authors would like to acknowledge Enova SF for founding the participation in the Annex. The authors are also grateful for the support from The Norwegian Research Council and partners through the EE Settlement and Flexbuilt research projects.

\section{References}

[1] S. Mamo, F. • Cecilie, and F. • Christoffer Venås, Grønt er ikke bare en farge: Barekraftige bygninger eksisterer allerede, 68th ed. Oslo: SINTEF akademisk forlag, 2020 .

[2] European Commission, "The European Green Deal, Building and renovation," 2019.

[3] J. Terés-Zubiaga, M. G. Almeida, O. Mørck, R. Bolliger, and D. Venus, "Potential of building renovation at district level for reducing $\mathrm{CO} 2$ emissions and fostering urban regeneration. IEA-EBC Annex 75," in Proceedings of 10th EUROPEAN CONFERENCE ON ENERGY EFFICIENCY AND SUSTAINABILITY IN ARCHITECTURE AND PLANNING, 2019.

[4] M. Conci and J. Schneider, "A District Approach to Building Renovation for the Integral Energy Redevelopment of Existing Residential Areas," Sustainability, vol. 9, no. 5, p. 747, May 2017.

[5] J. Terés-Zubiaga et al., "Cost-effective building renovation at district level combining energy efficiency \&amp; renewables Methodology assessment proposed in IEA EBC Annex 75 and a demonstration case study," Energy Build., vol. 224, p. 110280 , Oct. 2020.

[6] "Publications || IEA EBC || Annex 75." [Online]. Available: https://annex75.ieaebc.org/publications. [Accessed: 04-Jan-2021].

[7] "ProgramByggerne AS." [Online]. Available: https:/www.programbyggerne.no/. [Accessed:
04-Jan-2021].

[8] K. B. Lindberg, G. Doorman, D. Fischer, M. Korpås, A. Ånestad, and I. Sartori, "Methodology for optimal energy system design of Zero Energy Buildings using mixedinteger linear programming," Energy Build., vol. 127, pp. 194-205, Sep. 2016.

[9] Standards Norway, "Energy performance of buildings - Calculation of energy needs and energy supply (SN-NSPEK 3031:2020),” 2020.

[10] A. L. Sorensen, I. Sartori, K. B. Lindberg, and I. Andresen, "Analysing electricity demand in neighbourhoods with electricity generation from solar power systems: A case study of a large housing cooperative in Norway," in IOP Conference Series: Earth and Environmental Science, 2019, vol. 352, no. 1.

[11] L. Sørensen, K. B. Lindberg, H. T. Walnum, I. Sartori, U. R. Aakenes, and I. Andresen, "Heat analysis for energy management in neighbourhoods: Case study of a large housing cooperative in Norway," in IOP Conference Series: Materials Science and Engineering, 2019, vol. 609, no. 5, p. 052009.

[12] CEN (European Committee for standarization), "EN 15978: 2011 Sustainability of construction works - Assessment of environmental performance of buildings Calculation method." 2011.

[13] NVE, "Dokumentasjon for kostnadar i energisektoren," 2015. [Online]. Available: https://www.nve.no/energiforsyning/energifors yningsdata/dokumentasjon-for-kostnadar-ienergisektoren/. [Accessed: 07-Jan-2021].

[14] Norconsult Informasjonssystemer AS, "Norsk prisbok." 2020.

[15] I. Sartori, Å. L. Sørensen, R. Woods, and O. Wolfgang, "ZEN Case - Energisystem Risvollan: Analyse av energisystensløsninger, kostnader og beslutningsprosess for Risvollan borettslag," Trondheim, Norway, 2020.

[16] The Norwegian EPD Foundation, “EPD Norway." [Online]. Available: https://www.epd-norge.no/?lang=en_GB. [Accessed: 29-Jan-2021].

[17] Tensio, "Nettleiepriser 2020," 2020.

[18] "Lov om produksjon, omforming, overføring, omsetning, fordeling og bruk av energi m.m. (energiloven) [Norwegian]." .

[19] Standard Norge, "NS 3720:2018 Method for greenhouse gas calculations for buildings." $\mathrm{p}$. 40, 2018.

[20] Statkraft varme, "Lokale miljødata BREEAM.” [Online]. Available: https://www.statkraftvarme.no/omfjernvarme/klima-og-miljo/lokale-miljodata--breeam/. [Accessed: 29-Jan-2021]. 